\title{
Discourses, travel behaviour and the 'last mile' in London
}

\author{
Robin Hickman and Giacomo Vecia
}

Bartlett School of Planning, University College London, London, UK

\begin{abstract}
The concept of 'sustainable travel' has been well discussed for over three decades; yet the meaning of sustainability in travel remains interpreted in many different ways. A transition to more environmentally sustainable travel has proven difficult to achieve, particularly in suburban areas. For individuals in society there are many different aspirations for, and constraints on, travelling in an environmentally sustainable manner. Lack of modal choice, route options, the cost of using public transport, and wider cultural norms are a few of the barriers to realising a more sustainable transport network. Compounding this is the 'last mile' problem, concerning the facilities linking the main mode to the home, workplace or wider destination, which are often poor.

This paper explores both the perceptions and opinions of everyday commuters in Ealing, London, including consideration of their localised last mile issues. An in-depth study is undertaken with 35 employees of Ealing Council, using Q methodology to investigate the participants' perceptions towards, and awareness of, their respective journeys. The Q method analysis undertaken highlighted four major discourses associated with travel and the LMP in Ealing: 'the public transport user', 'the committed cyclist', 'the multi-modal traveller' and 'the frustrated traveller'. Understanding these different discourses and their unique characteristics has significant potential for assisting policymakers and planners in developing more targeted investment priorities, policies, and stakeholder engagement strategies.
\end{abstract}

\section{Key Words}

Q methodology, discourse analysis, travel behaviour, public transport, last mile.

\section{Paper citation:}

Hickman, R. \& Vecia, G. 2016. Discourses, travel behaviour and the 'last mile' in London. Built Environment, 42, 539-553.

https://doi.org/10.2148/benv.42.4.539 


\section{INTRODUCTION}

The resurgence in the popularity of urban living in the UK, the emerging phenomenon of 'peak car' (Goodwin and Van Dender, 2013), and increased usage of public transport, walking and cycling, offers much potential for greater environmental sustainability in travel behaviours. Transport planners and practitioners are keen to capitalise on increased urban populations and a growing consensus towards investing in public transit, walking and cycling. Despite this, significant barriers exist to more widespread use of the non-private car modes. In the UK, for instance, car ownership rates and vehicle kilometres remain high, particular in suburban areas and beyond the large urban areas (UK Department for Transport, 2015).

There are a number of factors that influence an individual's likelihood to use public transport, walking and cycling, and there is a significant literature to accompany the topic. Generally, it is agreed that some of the main factors influencing modal choice include: (1) sociodemographic factors such as income level, household status, race, gender, marital status, and others; (2) transit network characteristics such as network extent, service frequencies, hours of service, and ride cost; (3) built environment factors such as accessibility, density, and employment availability, among others; and (4) infrastructure design factors, such as the extent and quality of infrastructure (cycle lanes, connected footpaths), signage and wayposting, and route beautification measures, among others. Transit networks and the built environments that support and surround them can both facilitate and hinder more sustainable travel behaviour, particularly when considering the linkage between main travel modes and their first/last leg connecting journeys (Tilahun et al., 2016). Many of these factors include so-called 'last mile' issues and play an important role in unlocking more sustainable travel behaviours. The last mile, for the purposes of this paper, is defined as the potential gap between a traveller's main mode of travel access point (bus stop, Underground station, car park) and their home, workplace or wider destination. The journeys considered are those from the workplace to home and home to workplace. Understanding perceptions and opinions of last mile journeys within a particular context can provide important clues to encouraging more sustainable travel behaviours - it may be that the poor design of the last mile is the obstacle to encouraging more people to use public transport, walking and cycling.

This paper attempts to explore and discuss both the perceptions and opinions of everyday commuters in Ealing, London, relative to their journeys between home and work. Ealing known as 'the Queen of the Suburbs' - is a borough located in suburban West London, with high levels of public transport accessibility, including access to the London Underground network, and a high non-car mode share ${ }^{1}$. The borough has experienced an increase in the proportion of households without a car - from 31.7\% in 2001 to $35.3 \%$ in 2011 (Ealing Borough Council, 2014). Some interesting trends in travel behaviour appear to be emerging including the younger population cohorts using the private car much less than previous generations. The first part of the paper considers the discursive approach and how it might deepen our understanding of travel behaviours. The second part explores and tests a discursive survey approach - Q methodology - developing discourses on travel behaviours in the case

\footnotetext{
${ }^{1}$ Ealing is the third largest London borough in terms of its population, with a population of 338,000. It has excellent transport links and good access into central London. In terms of trips per day, the main modes are private car (42\%), walking (28\%), bus (16\%), Underground (8\%), cycle (3\%) and National Rail (2\%) and taxi (1\%) (Ealing Borough Council, 2014).
} 
study. The potential of the approach to generate meaningful data for interpreting travel behaviour motives and beliefs is also discussed.

\section{The Discursive ApProach AND Q MeThodology}

Debates about sustainable travel can be analysed in discursive terms, yet there are few studies that use discourse analysis in travel. There is a wider tradition in environmental studies for considering the discursive approach (Hajer, 1995, Barry and Proops, 1999, Hajer and Versteeg, 2005, Stevenson, 2015); but little in transport planning, with notable exceptions including Steg et al. (2001) considering instrumental, symbolic and affective motives for car use; Rajé (2007) on transport and social inclusion; and Jones et al. (2012) exploring cycling in urban areas in the UK. While some research has been conducted on the last mile through quantitative methods, such as multinomial logit and discrete choice models (Tilahun et al., 2016; Koh and Wong, 2013), there is less attention paid to more qualitative, discursive approaches; perhaps making light of the sociocultural and discursive elements of the last mile journey.

In considering travel behaviour discursively, we borrow from Dryzek (1997, p.9-10) where he defines a discourse as: " "... a shared way of apprehending the world. Embedded in language, it enables those who subscribe to it to interpret bits of information and put them into coherent stories or accounts [...] each discourse rests on assumptions, judgements, and contentions that provide the basic terms for analysis, debates, agreements and disagreements."

There are a multitude of approaches to analysing discourses, including the direct analysis of publications, speeches, conversations and attitudes, utilising approaches such as Critical Discourse Analysis (CDA). Each method attempts to explore the connections between language and communication, covering issues of knowledge, practice, rhetoric and power. The shape and structure and meaning of the identified discourses can be overt or hidden, and the choice of the analytical approach is carefully considered to better suit the particular research problem (Hajer, 1995).

The approach employed in this study, Q methodology, coins itself as a 'quali-quantitative' (Stevenson, 2015) approach, attempting to bridge and substantiate discursive findings with statistical analyses. Broadly speaking, it does this through linking the output of a survey-based statement-ranking factor analysis (similar to that of Attitudinal Surveys) with discursive analysis and qualitative interpretation of key statements and viewpoints. Unlike Attitudinal Surveys; however, Q method factor analysis does not attempt to determine explanatory variables outside of the statement set but instead looks to generate "coalitions of belief" within the participant set (Barry and Proops, 1999). Discrete typologies (discourses) are provided which represent a typical respondent sharing a typology's perspectives. This approach offers a unique way to find connections between discursive elements (such as the connection between a preferred maximum walking distance and a desire to see more investment in pedestrian facilities) while providing a structured and scientific approach to investigating the travel behaviour discourse. Although interpretations of the study results should be carefully made: "... as a result of the relatively small size and non-random nature of selection of Q study participants, any accounts revealed by the method should be seen as representative of discourses that could be found amongst [the] research's participants and not as generalizable to a wider public (Steelman and Maguire, 1999, p.470)", we suggest that this limitation does not directly impact its utility, as experiences of the journey are experienced within specific geographies traversed by the traveller (Tilahun et al., 2016).

\section{METHODOLOGY}


The Q methodology analysis explored in this research adopted a four stage approach: (1) generation and selection of statements - the Q sample; (2) administration of the Q sample to participants through interviews; (3) processing of collected data to extract 'typical' $Q$ sorts through factor analysis using Q software; and (4) discursive interpretation of typical Q sorts.

\subsection{Q sample design}

A set of statements were developed, representing the Q sample, covering attitudinal statements on travel to and from Ealing. The approach used in developing the Q sample can vary - some Q studies have prioritised the collection of Q statements through interviews with relevant parties (such as Barry and Proops, 1999), whilst others have sourced statements from the relevant literature (Brown, 1993, Rajé, 2007, McKeown and Thomas, 2013). For this study, statements were taken or paraphrased from Ealing BC transport strategy documents, the wider sustainable travel literature, relevant news articles and knowledge of transport issues in the local area, and then checked with officials from Ealing BC. Approximately 80 statements were prepared in this manner as the 'long list', with 44 statements eventually used in the Q sample.

A concourse matrix was used to filter collected statements for use in the Q sample to minimise statement selection bias (Brown, 1980). The statements were structured to reflect infrastructural, psychological and structural elements of travel practice (Steg, 2005, Shove, 2012), including material considerations (objects, infrastructure, built environment, hardware), and meaning and perception (attitudes, symbolic meaning, ideas, aspirations). The final Q sample had an approximately equal proportion of material and meaning statements. An example of each type of statement is provided in Table 1. The 'competency' element of social practice used by Shove (2012) is seen as less relevant to travel behaviours in this context and was poorly represented in the Q Sample "long list". There are some competency issues evident, such as the need for a driving license or level of skill required to ride a bicycle, but fewer competency issues relative to material or meaning issues.

Table 1: Example Q Statements

\begin{tabular}{|l|l|}
\hline $\begin{array}{l}\text { Material } \\
\text { considerations: (7) }\end{array}$ & $\begin{array}{l}\text { The public environment around my place of work affects } \\
\text { how I decide to travel there. }\end{array}$ \\
\hline Meaning: (6) & $\begin{array}{l}\text { Driving part of the way from home to work would become } \\
\text { more acceptable if we could use low emission vehicles or } \\
\text { electric cars. }\end{array}$ \\
\hline
\end{tabular}

\subsection{Administering the $Q$ sort to participants}

All research interviews were conducted at Ealing Borough Council (Ealing BC) offices in Ealing, West London, UK (Figure 1). Participants were employed by Ealing BC, a major employer in the borough. 
Figure 1: Ealing Town Hall, with nearby Underground, bus routes and surrounding neighbourhood

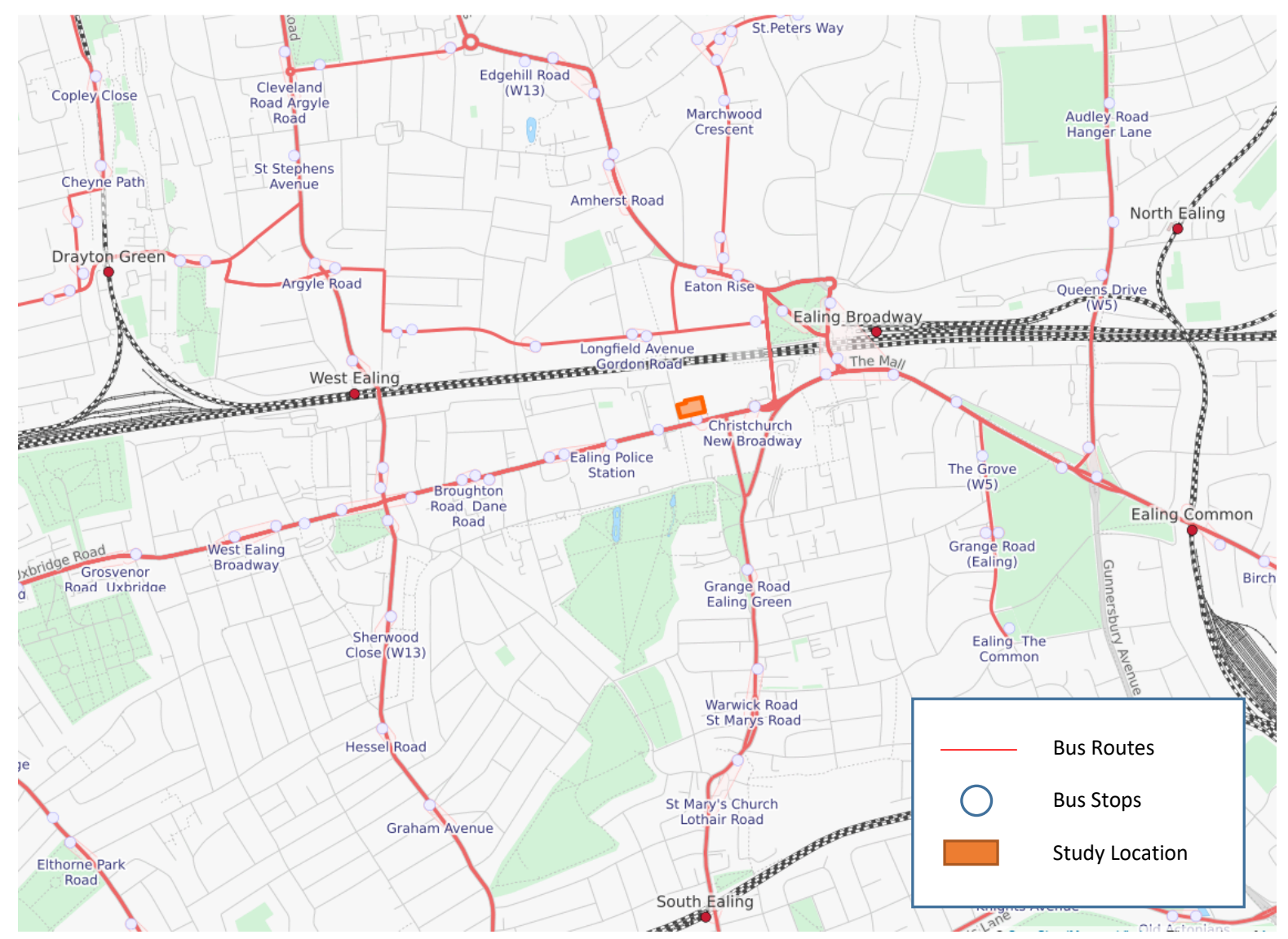

(OSM Open Data License, 2015)

Participants responded to a request for survey respondents made via the internal Ealing BC email network and a selection was made of first responses up to a total of 35. A summary of the participants (the P set) is given in Table 2.

Table 2: Interview participants

\begin{tabular}{|l|l|c|c|}
\hline \multicolumn{2}{|l|}{ Category } & Count & Percent \\
\hline \multirow{4}{*}{ Gender } & Male & 21 & $60.0 \%$ \\
\cline { 2 - 4 } & Female & 14 & $40.0 \%$ \\
\hline \multirow{2}{*}{$\begin{array}{l}\text { Age } \\
\text { group }\end{array}$} & $18-24$ & 4 & $11.4 \%$ \\
\cline { 2 - 4 } & $25-44$ & 13 & $37.1 \%$ \\
\cline { 2 - 4 } & $45-64$ & 18 & $51.4 \%$ \\
\hline \multirow{2}{*}{$\begin{array}{l}\text { Lar } \\
\text { License }\end{array}$} & Yes & 25 & $71.4 \%$ \\
\cline { 2 - 4 } $\begin{array}{l}\text { Main } \\
\text { mode, } \\
\text { journey to } \\
\text { work }\end{array}$ & No & 10 & $28.6 \%$ \\
\cline { 2 - 4 } & Bicycle & 11 & $31.4 \%$ \\
\cline { 2 - 4 } & $\begin{array}{l}\text { Car driver or } \\
\text { passenger }\end{array}$ & 4 & $22.9 \%$ \\
\cline { 2 - 4 } & Train & 3 & $11.4 \%$ \\
\cline { 2 - 4 } & Underground & 5 & $14.3 \%$ \\
\cline { 2 - 4 } & Foot & 4 & $11.4 \%$ \\
\hline
\end{tabular}




\begin{tabular}{|l|l|c|c|}
\hline \multirow{3}{*}{$\begin{array}{l}\text { Individual } \\
\text { income }\end{array}$} & $>£ 10,000$ & 1 & $2.9 \%$ \\
\cline { 2 - 4 } group & $£ 10-24,000$ & 8 & $22.9 \%$ \\
\cline { 2 - 4 } & $£ 25-39,000$ & 13 & $37.1 \%$ \\
\cline { 2 - 4 } & $£ 40-64,000$ & 12 & $34.3 \%$ \\
\cline { 2 - 4 } & $£ 65-99,000$ & 1 & $2.9 \%$ \\
\hline
\end{tabular}

Respondents were mostly male $(60 \%)$, in the $25-64$ age group $(89 \%)$ and with individual incomes between $£ 25-64,000$ (71\%), which is fairly representative of employees in the borough. The main mode for the journey to work includes a high proportion of cyclists $(31 \%)$ and few car drivers $(11 \%)$ - hence there is some bias in the participants towards cycling, though this is probably fairly representative of employees at Ealing BC. Respondents mostly live across West London, including some in Ealing; but also in neighbouring areas such as Greenford, Hanwell and Acton; and further afield such as Clapham, Feltham and High Wycombe. The results of the analysis are not interpreted to be representative of the borough or of Ealing BC, but only of the respondents themselves.

The Ealing BC offices were chosen due to their unique position at the western edge of the London Underground network and the proximity to a National Rail line (Great Western), numerous bus routes, a car park, and walking and cycling facilities. Commuting by car is difficult for Ealing BC employees as there are congested roads in the peak periods, expensive parking in the town centre ( $£ 10$ per day), no dedicated parking spaces for Ealing BC employees, and residential parking restrictions meaning that commuters cannot park in surrounding residential streets. Each of the potential public transport modes are likely to have a walking or cycling element as the initial and final part of the door-to-door journey from work to home and home to work. This variety in modal choice, alongside a high likelihood of last mile journeys due to limited parking facilities available at and near the site, made the location well suited for the last mile related investigation conducted in this study.

Survey respondents were invited for a 45-minute meeting during which a series of biographic, demographic, and other questions were asked. Participants were given a Q sort to complete and the responses were discussed following the statement ranking. Each participant was required to assign a score between -4 and +4 to the 44 statements, where -4 reflected statements they disagreed with most and +4 reflecting statements they agreed with most ${ }^{2}$. Participants were also limited in the number of statements they could assign to each score value, hence forced to sort in a normal distribution. The breakdown of score allocation limits is shown in Table 3. This 'forcing' of the Q sort (Cross, 2005, p.208) "...encourages participants to give careful consideration to the ranking they wish to achieve" (Barry and Proops, 1999, p.341). The survey ranking proved to be an engaging exercise for participants, with the forcing of the survey distribution often commented on as generating "significant introspection" (Participant 14) and "creating an awareness of priorities that didn't exist before [the study]" (Participant 27).

\footnotetext{
${ }^{2}$ Brown (1993: 102) notes that the range and distribution shape of statement score limitations have no effect on further analysis (as long as the distribution shape follows a quasi-normal distribution [Exel, 2005: 6]) and can be changed to fit the needs of each individual study.
} 
Table 3: Distribution of 'forced' rankings

\begin{tabular}{llllllllll} 
& \multicolumn{3}{l}{ Agree with least } & \multicolumn{4}{c}{ Agree with most } \\
Value & -4 & -3 & -2 & -1 & 0 & 1 & 2 & 3 & 4 \\
$\begin{array}{l}\text { Number of } \\
\text { Statements }\end{array}$ & 3 & 4 & 5 & 6 & 8 & 6 & 5 & 4 & 3 \\
$(\mathrm{n}=44)$ & & & & & & & & &
\end{tabular}

Following the completion of the Q sort, participants were then given the opportunity to comment on the overall themes that emerged from their personal ranking, and also why they felt passionately about their 'strongest' ranked statements (i.e. those ranked at -4 and 4). Some of these statements were used as further guidance when constructing the discourses derived from the factor analysis process.

\subsection{Factor Analysis}

All analyses within this Q study were conducted using PQMethod ${ }^{3}$, an open source Q methodology software programme. The PQMethod process follows the following generalised steps:

- Entering and assignment of Q sort data;

- Error proofing and validation;

- Principle Component Analysis (PCA) and preliminary factor flagging;

- VARIMAX factor rotation; and

- Analysis of rotated factors.

The full process executed in PQ Method closely follows both Barry and Proops (1999) and Rajé (2007). While each Q study merits critical discussion on the interpretation of PCA outputs and the selection of an appropriate number of factors given PCA eigenvalues, numbers of distinguishing statements, and factor exemplars (Watts and Stenner, 2005), this study has chosen to focus on presenting and discussing the factor typologies generated from PQ Method rather than dissecting these aforementioned choice-points. Nevertheless, a PCA results table (for the first 10 factors) and a factor loading matrix for four factors is provided below in Table 4 and Table 5 respectively.

Table 4: Results of the Principle Component Analysis

\begin{tabular}{llll}
\hline Factor & Eigenvalues & As Percentages & \\
\hline 1 & 7.17 & 20.49 & Cumulative Percentages \\
2 & 4.14 & 11.83 & 20.49 \\
3 & 2.75 & 7.87 & 32.32 \\
4 & 2.25 & 6.44 & 40.19 \\
5 & 1.96 & 5.61 & 46.63 \\
6 & 1.68 & 4.81 & 52.24 \\
7 & 1.54 & 4.41 & 57.05 \\
8 & 1.50 & 4.29 & 61.45 \\
9 & 1.32 & 3.78 & 65.75 \\
10 & 1.23 & 3.52 & 69.53 \\
& & & 73.05
\end{tabular}

3 PQMethod was developed by John Atkinson and Steven Brown, and adapted by Peter Schmolck. The manual consulted for analysis with PQMethod can be found at http://schmolck.userweb.mwn.de/qmethod/pqmanual.htm\#qcent. 
In Varimax rotation, factor loadings (correlation coefficients) are used to determine how individual Q sorts relate to each identified factor or discourse. Significant factor loadings are determined through finding values which are statistically significant generally to $p<0.01$ when compared against the study's standard error (McKeown and Thomas, 2013, p.53; calculated as $S E=2.58\left(\frac{1}{\sqrt{N}}\right)$ where $\mathrm{N}$ is the number of items in the $\mathrm{Q}$ sample). Thus, Q sort factor loadings greater than 0.33 were considered significant for this study.

Table 5: Factor loading matrix with four factors

\begin{tabular}{|c|c|c|c|c|c|c|c|c|}
\hline \multirow[b]{2}{*}{ Participant ID } & \multicolumn{8}{|c|}{ Factor } \\
\hline & 1 & & 2 & & 3 & & 4 & \\
\hline P01 & 0.43 & $X$ & 0.03 & & -0.11 & & -0.01 & \\
\hline P02 & 0.48 & & 0.48 & & 0.21 & & 0.32 & \\
\hline P03 & 0.31 & & 0.22 & & 0.51 & $X$ & 0.00 & \\
\hline P04 & 0.39 & & 0.37 & & 0.64 & $\mathrm{X}$ & -0.14 & \\
\hline P05 & 0.36 & & -0.38 & & 0.19 & & 0.45 & $\mathrm{X}$ \\
\hline P06 & 0.26 & & 0.33 & & 0.36 & & 0.09 & \\
\hline P07 & 0.05 & & 0.12 & & 0.16 & & 0.59 & $X$ \\
\hline P08 & 0.11 & & 0.67 & $X$ & 0.00 & & -0.02 & \\
\hline P09 & 0.04 & & 0.09 & & 0.58 & $X$ & 0.14 & \\
\hline P10 & 0.45 & $X$ & 0.02 & & 0.36 & & -0.11 & \\
\hline P11 & 0.14 & & -0.07 & & -0.03 & & 0.74 & $\mathrm{X}$ \\
\hline $\mathrm{P} 12$ & 0.44 & $X$ & 0.19 & & 0.23 & & 0.22 & \\
\hline $\mathrm{P} 13$ & 0.77 & $X$ & 0.66 & & 0.17 & & -0.24 & \\
\hline P14 & 0.77 & $X$ & 0.29 & & -0.02 & & -0.06 & \\
\hline P15 & 0.49 & & 0.57 & $X$ & -0.10 & & -0.01 & \\
\hline P16 & 0.05 & & 0.61 & $X$ & 0.24 & & 0.08 & \\
\hline P17 & 0.70 & $X$ & 0.07 & & 0.10 & & 0.25 & \\
\hline P18 & 0.03 & & 0.37 & & -0.03 & & 0.09 & \\
\hline P19 & 0.67 & $X$ & 0.06 & & 0.09 & & 0.04 & \\
\hline $\mathrm{P} 20$ & 0.46 & & -0.11 & & 0.09 & & 0.46 & \\
\hline P21 & 0.36 & & 0.55 & $X$ & -0.34 & & -0.01 & \\
\hline P22 & 0.42 & & 0.68 & $X$ & -0.06 & & -0.25 & \\
\hline P23 & -0.04 & & 0.43 & & 0.50 & $X$ & -0.01 & \\
\hline P24 & 0.34 & & 0.11 & & 0.16 & & 0.09 & \\
\hline P25 & -0.03 & & 0.51 & $X$ & 0.17 & & 0.35 & \\
\hline P26 & 0.41 & & 0.30 & & 0.03 & & 0.56 & $X$ \\
\hline P27 & 0.67 & $X$ & -0.25 & & 0.02 & & 0.03 & \\
\hline P28 & 0.24 & & -0.08 & & 0.70 & $X$ & 0.09 & \\
\hline P29 & -0.15 & & 0.77 & $X$ & 0.07 & & -0.13 & \\
\hline P30 & 0.19 & & 0.32 & & -0.67 & $X$ & 0.01 & \\
\hline P31 & 0.16 & & 0.25 & & 0.46 & $X$ & 0.42 & \\
\hline P32 & -0.35 & & -0.19 & & -0.22 & & 0.56 & $X$ \\
\hline P33 & 0.14 & & -0.03 & & 0.20 & & 0.04 & \\
\hline P34 & 0.32 & & 0.21 & & -0.26 & & -0.35 & \\
\hline P35 & -0.40 & & 0.68 & $X$ & 0.16 & & 0.02 & \\
\hline
\end{tabular}

$X$ indicates the preferred loading of a sort onto a factor 


\section{DISCURSIVE INTERPRETATION}

The analysis carried out within PQMethod produced the following set of distinct factors or discourses concerning sustainable travel and the last mile problem within the $\mathrm{P}$ set:

- Discourse A - 'The Public Transport User'

- Discourse B - 'The Committed Cyclist'

- Discourse C - 'The Multi-modal Traveller'

- Discourse D - 'The Frustrated Traveller'

These discourses can be taken as unique, coherent typologies of the collective patterns of shared opinions and beliefs held by groups of study participants (McKeown and Thomas, 2013). The labels given to the discourses are derived by the authors in view of the responses to the statements. Table 6 shows the factorised ranking of each statement in each discourse as developed through PQMethod analysis. Of particular interest in constructing the characteristics of each discourse are those statements ranked highest and lowest $(-4,-3,+3$, and +4$)$, as discussed in Barry and Proops (1999) and Rajé (2007). These statements are the defining features of the factor that emerged from $Q$ analysis and are seen as a large part of the “...substance of each factor" (Stevenson, 2015). Additionally, those statements ranked at 0 can provide meaningful insight into the topics deemed most neutral or insignificant by participants (Rajé, 2007). All statements falling under these values are provided below and are the basis for the discourses identified ${ }^{4}$.

The research allows us to understand the detailed nuances in viewpoints on sustainable transport, including the views and coalitions of views on current behaviours and potential policy measures. The findings are specific to the respondents interviewed concerning their commutes to work within Ealing; though there is perhaps wider relevance for travel in other suburban centres in London and in other neighbourhoods which share similar spatial and demographic characteristics abroad. An important feature is the level and range of debate relative to the particular context. The problematic and slow transition towards more sustainable travel behaviours is common in most contemporary industrialised cities - though with very different features by context. This type of analysis gives a rich understanding of the viewpoints in a particular context; an understanding that is arguably more difficult to capture through more commonly applied quantitative approaches.

Stevenson (2015, p.6) reminds us of the complex relationship between the 'Q researcher' and the data analysis process conducted through PQMethod, stating: “... while a set of statistical criteria can ultimately determine whether a solution is accurate and valid, Q methodological factor analysis is a deeply interpretive and qualitative process [...] the scope for interpretation is by no means boundless: the data will only reveal relationships among the variables that actually exist, it is then the role of the researcher to decide which relationships make most substantive sense". With this in mind, interpretive descriptions have been provided below for the four discourses alongside the number of participants who 'loaded' 5 onto that particular factor.

\footnotetext{
${ }^{4}$ Note: Five of the 36 participants in this study were not sorted into a relevant discourse. These individuals were "confounded" and did not strongly enough correlate to any one discourse so as to be represented by it.

${ }^{5}$ Participants are said to be loaded onto a particular factor meaning that their unique Q sort identified more closely to that particular discourse or typology than any others.
} 
Table 6: Statements and associated scores for four constructed discourses

\begin{tabular}{|c|c|c|c|c|c|}
\hline \multirow[t]{2}{*}{ No. } & \multirow[t]{2}{*}{ Statement } & \multicolumn{4}{|c|}{ Statement By Discourse } \\
\hline & & $\begin{array}{c}\text { A } \\
\text { PT User }\end{array}$ & $\begin{array}{c}\text { B } \\
\text { Committed } \\
\text { Cyclist } \\
\end{array}$ & $\begin{array}{c}\text { C } \\
\text { Multi-modal } \\
\text { Traveller }\end{array}$ & $\begin{array}{c}\mathrm{D} \\
\text { Frustrated } \\
\text { Traveller }\end{array}$ \\
\hline 1 & $\begin{array}{l}\text { I sometimes choose to extend the walking portion of my trip } \\
\text { to my final destination }\end{array}$ & 3 & 1 & -1 & -4 \\
\hline 2 & $\begin{array}{l}\text { There are a number of travel options for getting from home } \\
\text { to work giving me significant flexibility }\end{array}$ & 3 & 3 & 0 & -3 \\
\hline 3 & $\begin{array}{l}\text { I try to end my journey by motorised transport/bike as close } \\
\text { to my destination as possible to minimise walking }\end{array}$ & -3 & -2 & -2 & 2 \\
\hline 4 & $\begin{array}{l}\text { There is a clear maximum distance I am willing to walk from } \\
\text { any bus stop/station to my final destination }\end{array}$ & -3 & -2 & -1 & 4 \\
\hline 5 & $\begin{array}{l}\text { The price and availability of parking spaces at my destination } \\
\text { affects my choice of transport mode }\end{array}$ & 2 & -3 & 2 & 0 \\
\hline 6 & $\begin{array}{l}\text { Driving part of the way from home to work would become } \\
\text { more acceptable if we could use low emission vehicles or } \\
\text { electric cars }\end{array}$ & 0 & -2 & 2 & 0 \\
\hline 7 & $\begin{array}{l}\text { The public environment around my place of work affects how } \\
\text { I decide to travel there }\end{array}$ & -1 & 1 & -1 & -4 \\
\hline 8 & $\begin{array}{l}\text { Car parking is much too expensive and restrictive around } \\
\text { Ealing Broadway }\end{array}$ & 1 & -3 & 2 & 2 \\
\hline 9 & I enjoy the walk from the car park into Ealing town centre & 0 & -1 & 0 & 0 \\
\hline 10 & $\begin{array}{l}\text { There needs to be much more car parking space in Ealing } \\
\text { town centre - and it should be much cheaper }\end{array}$ & 0 & -4 & 0 & 1 \\
\hline 11 & $\begin{array}{l}\text { Residential parking zones in Ealing are much too restrictive } \\
\text { - I can never find a space to park }\end{array}$ & 4 & -4 & 2 & 1 \\
\hline 12 & $\begin{array}{l}\text { I prefer to use public transport as my main mode of travel and } \\
\text { any further travel to my destination is dependent on this }\end{array}$ & 3 & 2 & -3 & -2 \\
\hline 13 & The last mile of my journey is the part I enjoy the most & 4 & -1 & -1 & 0 \\
\hline 14 & $\begin{array}{l}\text { The last mile of a journey should be kept as short as possible, } \\
\text { particularly when that link consists of walking or cycling }\end{array}$ & 2 & -1 & -1 & 2 \\
\hline 15 & $\begin{array}{l}\text { A poor link in a journey, such as the last mile, means I tend } \\
\text { to drive my car }\end{array}$ & -4 & -4 & 0 & 0 \\
\hline 16 & I enjoy cycling to/from my main journey on public transport & -3 & 0 & 4 & -2 \\
\hline 17 & $\begin{array}{l}\text { I would consider changing my main mode of travel if the last } \\
\text { mile of my journey was made more attractive }\end{array}$ & -2 & -2 & -1 & -1 \\
\hline 18 & $\begin{array}{l}\text { Restricting car usage in Ealing is critical to the success of the } \\
\text { town centre }\end{array}$ & -3 & 4 & -2 & -2 \\
\hline 19 & The cycle parking facilities in Ealing are good & 0 & 0 & 3 & 2 \\
\hline 20 & Waiting for public transport is the worst part of my journey & 2 & 1 & 1 & 3 \\
\hline 21 & $\begin{array}{l}\text { Stopping at facilities (such as cafes/groceries) in or near my } \\
\text { local station is a common part of my home to work journey }\end{array}$ & 0 & 0 & 0 & -4 \\
\hline 22 & $\begin{array}{l}\text { Ealing needs a tram along Uxbridge Road to help improve } \\
\text { the quality of public transport provision }\end{array}$ & -2 & 1 & -3 & -1 \\
\hline 23 & $\begin{array}{l}\text { Public transport into and out of central London is fine from } \\
\text { Ealing - the main problem is travelling north, south, and } \\
\text { orbitally. }\end{array}$ & 1 & 3 & 4 & 1 \\
\hline 24 & $\begin{array}{l}\text { Ealing Broadway needs to be made much more attractive as } \\
\text { a station - with a better waiting environment and improved } \\
\text { facilities }\end{array}$ & 0 & 4 & 3 & -1 \\
\hline 25 & $\begin{array}{l}\text { It is not safe to walk in the early mornings/late evenings } \\
\text { to/from my local bus stop/station }\end{array}$ & -4 & -2 & -3 & -1 \\
\hline 26 & $\begin{array}{l}\text { The walk to and from my local stop/station is often the best } \\
\text { part of my journey }\end{array}$ & 1 & 0 & 0 & -3 \\
\hline 27 & $\begin{array}{l}\text { The interchange between Underground/rail and bus is good } \\
\text { at Ealing Broadway - there is little time to wait }\end{array}$ & 4 & 0 & 0 & 1 \\
\hline 28 & $\begin{array}{l}\text { The poor quality of the urban environment around my house } \\
\text { means I don't walk so much }\end{array}$ & -4 & -3 & -4 & -3 \\
\hline 29 & I do not have space to park a bicycle at home & -1 & -1 & -4 & -1 \\
\hline 30 & $\begin{array}{l}\text { We should spend much more on the public realm } \\
\text { improvements to make it more pleasant for pedestrians }\end{array}$ & 2 & 2 & 1 & 4 \\
\hline
\end{tabular}



space for footways and at crossings should be given to pedestrians

32 There are too many buses parked around Haven Green Ealing needs a designated bus station

33 There should be segregated cycle paths along Uxbridge Road and other main roads in Ealing

34 Heavy traffic around stations makes it difficult to cycle safely

35 A cycle hire system is an important part of a well-connected neighbourhood

36 My home to work journey changes significantly with daily weather conditions

37 Stations should prioritise cycle parking over car parking

38 House price affordability is a huge problem in Ealing and much of West London - it means I cannot live close to where I work

39 Taxis get too much of a priority position outside Ealing Broadway - they shouldn't be located in front of Haven Green

40 Haven Green is a valuable resource for Ealing - the pedestrian spaces there should be protected and enhanced

41 There is too much vehicular traffic in the centre of Ealing we should seek to remove some of it from the roads around Haven Green

42 It is important for businesses that cars can access and park in Ealing - we should seek to improve highway capacity and car parking facilities

43 New development in central Ealing should be of a higher density so that more people can live and work in the town centre

44 The quality of the retail environment could be much improved in Ealing - I would shop more locally if it was

$\begin{array}{cccc}1 & 2 & 1 & -1 \\ -1 & 1 & -2 & -2 \\ 2 & 4 & 2 & 3 \\ -1 & 2 & -3 & 2 \\ 0 & 0 & 1 & 1 \\ -2 & 0 & -4 & 3 \\ 0 & 3 & 3 & -2 \\ 3 & -1 & -2 & 4 \\ -2 & 0 & 0 & -3 \\ 1 & 2 & 1 & 3 \\ -2 & 3 & 3 & 0 \\ 1 & -3 & 1 & 1 \\ -1 & -1 & -2 & 0 \\ -1 & 1 & 4 & 0\end{array}$

\section{Discourse A - The Public Transport User}

Discourse A is formed by seven participants and is represented by the statements shown in Table 7. The discourse is constructed from the given statements whilst factor loadings are used to determine how individual Q sorts relate to each discourse.

Table 7: Distribution of most agreed with, neutral, and least agreed with statements for Discourse A

\begin{tabular}{ll}
\hline Rank & Statements \\
\hline 4 & $11,13,27$ \\
3 & $1,2,12,38$ \\
0 & $6,9,10,19,21,24,35,37$ \\
-3 & $3,4,15,18$ \\
-4 & 25,28
\end{tabular}

The Public Transport User discourse is primarily composed of a positive attitude towards public transport infrastructure linkages and interchanges around Ealing Broadway (27) and of having a clear preference in usage and reliance on public transport as a primary means of travel (12). The Public Transit User rejects that poor linkages existed in their journey (15) and instead finds that there are a number of travel options available to them (2). These individuals feel safe at all times when travelling to and from public transport stations and stops (25) and do not feel that they have a clear maximum distance they are willing to walk from these stops to their final 
destination (4). A statement from one of the respondents is given below, illustrating the type of viewpoints evident:

"We need to rebalance the road for everyone. We can't be anti-car but we need to make sure that roads are usable for all essential journeys."

While there were different potential factors as to why Public Transport Users travelled in this way - namely the restrictive nature of parking in central Ealing (11) and the lack of house price affordability in Ealing preventing them from living closer to work (38) - these participants scored the enjoyment of their last mile as the highest of all discourses (13) and would even sometimes opt to extend the walking portion of the last mile of their journey (1). Interestingly, Public Transit Users did not support the idea that further car restrictions in Ealing are critical to the success of the town centre (18), nor do they enjoy cycling (16) suggesting that they prefer all types of motorised transport over cycling.

Discourse B - The Committed Cyclist

Discourse B is formed by eight respondents and is represented by the statements shown in Table 8.

Table 8: Distribution of most agreed with, neutral, and least agreed with statements for Discourse B

\begin{tabular}{ll}
\hline Rank & Statements \\
\hline 4 & $18,24,33$ \\
3 & $2,23,37,41$ \\
0 & $16,19,21,26,27,35,36,39$ \\
-3 & $5,8,28,42$ \\
-4 & $10,11,15$
\end{tabular}

The Committed Cyclist discourse is the most anti-car of all discourses, strongly believing that restricting car usage in central Ealing is key to the success of the town centre (18), there is too much car traffic in central Ealing (41), there should not be any additional parking facilities added in Ealing town centre (10), parking zones are not too restrictive (11), car parking is not expensive and restrictive enough around Ealing Broadway (8), and that car access into central Ealing is not important to the success of businesses in the area (42). A statement from one of the respondents is given below, illustrating the type of viewpoints evident:

\section{"Ealing Borough Council needs to get a lot more radical with cycling infrastructure and shouldn't worry about prioritising over the car driver!"}

The Committed Cyclist prioritises the addition of segregated cycle paths along Uxbridge Road and other main roads in Ealing (33) higher than any other statement, and similarly believes that cycle parking should be prioritised over car parking at public transport stops and stations (37), and that Ealing Broadway should be made much more attractive as a station, with a better waiting environment and improved facilities (24). While the Committed Cyclist is clearly procycle and anti-car, participants are neutral towards both the state of cycling facilities in Ealing (19) and towards the belief that a cycle hire system is seen as an important part of a wellconnected neighbourhood (35). This suggests that these individuals would cycle regardless of 
the current state of cycle infrastructure or provision - many of these types of cyclists appear relatively confident cycling on congested roads without good quality segregated routes.

Discourse C-The Multi-modal Traveller

Discourse $\mathrm{C}$ is formed by seven respondents ${ }^{6}$ and is represented by the statements shown in Table 9.

Table 9: Distribution of most agreed with, neutral, and least agreed with statements for Discourse C

\begin{tabular}{ll}
\hline Rank & Statements \\
\hline 4 & $16,23,44$ \\
3 & $19,24,37,41$ \\
0 & $2,9,10,15,21,26,27,39$ \\
-3 & $12,22,25,34$ \\
-4 & $28,29,36$
\end{tabular}

The Multi-modal Traveller is the discourse most appreciative of multi-modal options, perhaps reflecting different modes being chosen on different days. Similar to the Committed Cyclist, the Multi-modal Traveller believes that there is too much vehicular traffic in the centre of Ealing (41) and that public transport stations should prioritise cycle parking over car parking (37). They strongly enjoy cycling to and from their main journey on public transport (16), believing that cycle parking facilities in Ealing are good (19), and that heavy traffic around stations does not making cycling unsafe (34). These perspectives are coupled with their belief that Ealing Broadway station should be made more attractive with improved facilities (24), and that public transport into and out of central London was fine from Ealing - the main problem being journeys north, south and orbitally (23). A statement from one of the respondents is given below, illustrating the type of viewpoints evident:

"Policy should encourage more public transport usage and cycling amongst the population, and less car usage."

This narrative points to a multi-modal approach to their regular transport needs, incorporating a variety of modal choices in junction with their cycling trips. Unique to the Multi-modal Traveller discourse is the belief that the retail environment could be much improved in Ealing (44), suggesting that these travellers are more likely to incorporate commercial trips into their daily travel patterns.

\section{Discourse D - The Frustrated Traveller}

Discourse D is formed by five respondents and is represented by the statements shown in Table 10.

Table 10: Distribution of most agreed with, neutral, and least agreed with statements for Discourse D

Rank Statements

\footnotetext{
${ }^{6}$ One respondent loaded negatively onto Discourse C. Their bipolar discourse, not included as part of Discourse $\mathrm{C}$, is the inverse of Discourse $\mathrm{C}$ and can be interpreted as similar to that of Discourse A - Public Transport User.
} 


\begin{tabular}{ll}
\hline 4 & $4,30,38$ \\
3 & $20,33,36,40$ \\
0 & $5,6,9,13,15,41,43,44$ \\
-3 & $2,26,28,39$ \\
-4 & $1,7,21$
\end{tabular}

The Frustrated Traveller discourse has a distinctly pessimistic and negative tone, especially regarding cycling and pedestrian facilities. Individuals demonstrated that there is a clear maximum distance they are willing to walk from any bus stop or station to their final destination (4) and that they do not extend the walking portion of their trip to their final destination (1). The Frustrated Traveller also believes that we should spend much more on the public realm to make it more pleasant for pedestrians (30), that the pedestrian spaces in Haven Green are a valuable resource for Ealing and should be protected and enhanced (40), and that house price affordability is a huge problem in Ealing and much of West London (38). This suggests fairly long and perhaps complex journeys to work. In regards to other modes, Frustrated Travellers find waiting for public transport the worst part of their journey (20), that there are not many travel options for getting to and from work (2), and that there should be more segregated cycle paths in Ealing (33). Despite these negative opinions towards a number of modes, daily weather conditions have a significant impact on their home to work journeys (36), suggesting Frustrated Travellers take a more adaptable and varied approach to daily travel needs similar to the Multimodal Traveller. A statement from one of the respondents is given below, illustrating the type of viewpoints evident:

"I would prefer to cycle more and use the car less really. I'm not much of a fan of buses, however, and don't use the tube much as I don't go into central London often."

\section{CONCLUSIONS}

It is increasingly recognised that transport planning, if it is to encourage greater sustainability in travel, needs to continue to radically improve infrastructure for public transport, walking and cycling, but also to go beyond infrastructure planning to examine and shape the psychological and structural elements of travel. A private car mode share of $42 \%$ in the case study of Ealing, (Ealing Borough Council, 2014) is relatively low yet it can arguably be reduced much more through significantly higher levels of cycling, increased use of the Underground, National Rail and greater bus patronage, for instance (see for reference the different cities describe by Tight et al., This issue).

The discourses identified in the analysis are specific to the respondents interviewed in the Ealing context, focused around the use and perceived quality of public transport, walking and cycling, including last mile issues. There is much variety in the viewpoints on travel and it is interesting that there is no specific pro-car user discourse. This perhaps reflects the respondents interviewed, but also the difficulty in commuting by car to Ealing. Initiatives to reduce private car travel are relatively well advanced, certainly car parking restraint is well applied - there are few spaces and it is very expensive to park. Alongside there is an extensive public transport system, though mainly only in a west-east direction, into and out of London. North-south and orbital services can be much improved. Cycling facilities are very poor, yet there is still a significant cohort who are keen on cycling despite the conditions. Of course, if cycling's appeal is to be broadened, much better facilities are required, including segregated lanes and better 
cycle parking facilities. House price affordability is a critical problem in Ealing (with average house prices running at well over ten times average household incomes, as of 2016). This is affecting many journeys, as people are forced to live further away from work than they might wish, with the Public Transport Users and Frustrated Travellers perceiving this as a large problem.

In terms of the last mile issues, these are also very specific to the Ealing context. The Public Transport Users sometimes choose to extend the walking portion of their trips; the Frustrated Travellers do not; the Committed Cyclists are not affected by the price and availability of car parking at the destination; whilst Public Transport Users believe residential parking zones are much too restrictive, suggesting that they might like to use the car given the chance, though they also perceive the last mile of the journey is the part they enjoy most. They also believe that the interchange between Underground/Rail and bus is good. Only the Multimodal Traveller enjoys cycling to and from the main journey on public transport. All discourses believe it is safe to walk at all times of the day, that we should spend more on public realm improvements to make it more pleasant for pedestrians, and that there should be segregated cycle paths along the main roads in Ealing. There is a great opportunity to improve walking and cycling facilities as the 'glue' that provide access between public transport hubs and origins/destinations.

Discourse analysis, as an empirical method, offers much potential to help understand the different viewpoints of the public on the constraints of their current travel behaviours and the potential for taking up emerging policy measures. Q methodology, in particular, has strengths as a qualitative-quantitative approach for use alongside the more conventional quantitative methods employed in transport planning. It is most suited to exploring issues where there are different views to be understood or some element of controversy to be explored (Stevenson, 2015) and can feasibly be used in strategy making, project appraisal and participatory processes around major projects. Understanding the different discourses and their unique characteristics has significant potential for assisting policymakers and planners in developing more targeted investment priorities, policies, and stakeholder engagement strategies.

This analysis of the subtleties in people's views, including on travel and potential new policy measures, can give a richness to our understanding that purely quantitative approaches often fail to achieve. For example, the use of new infrastructure relies, in part, on subjective experience and personal opinion. This is likely to differ by individual with different groups of viewpoints identifiable - but this range of opinion is largely ignored in project development. In empirical terms it would be interesting to test the robustness and representativeness of discourses if larger samples could be taken, including how views might change over time, and before and after large infrastructure investments. Perhaps, to an extent, the attitudes will change, indeed follow, the infrastructure investment? If we can further understand these types of nuances in attitudes relative to sustainable travel options - and the coalitions of viewpoints that might appear in a particular context - then perhaps policy measures can be much more effectively targeted towards different population cohorts The current one-size-fits-all policy making, which is conventionally used, is a fairly simplistic view of project implementation. It is clear that transport planners need to think beyond the infrastructure and the built environment to also influence individual attitudes to travel and the societal constraints on travel. If we can be more successful along these dimensions, then perhaps the move away from the use of the private car can become much more significant. 


\section{References}

BARRY, J. and PROOPS, J. 1999. Seeking sustainability discourses with Q methodology. Ecological Economics, 28, 337-345.

BROWN, S. 1993. A primer on Q methodology. Operant Subjectivity, 91-138.

BROWN, S. R. 1980. Political Subjectivity: Applications of Q Methodology in Political Science, New Haven, Yale University Press.

CROSS, R. M. 2005. Exploring attitudes: The case for Q methodology. Health Education Research, 20, 206-213.

DRYZEK, J. 1997. The Politics of the Earth: Environmental Discourses, Oxford, Oxford University Press.

EALING BOROUGH COUNCIL 2014. Local Implementation Plan. Transport Delivery, 2014 - 2017 Ealing.

GOODWIN, P. and VAN DENDER, K. 2013. 'Peak Car' - Themes and Issues. Transport Reviews, 33, 243254.

HAJER, M. and VERSTEEG, W. 2005. A decade of discourse analysis of environmental politics: Achievements, challenges, perspectives. Journal of Environmental Policy and Planning, 7, 175184.

HAJER, M. A. 1995. The Politics of Environmental Discourse: Ecological Modernization and the Policy Process, Oxford, Clarendon Press.

JONES, T. ET AL. 2012 'Moving around the city: discourses on walking and cycling in English urban areas'. Environment \& Planning A, Vol 44 (6), pp 1407-1424.

$\mathrm{KOH}, \mathrm{P}$. P., WONG, Y. D. 2013. Comparing pedestrians' needs and behaviours in difference land use environments. Journal of Transport Geography. 26, 43-50.

MCKEOWN, B. and THOMAS, D. B. 2013. Q Methodology, Thousand Oaks, California, SAGE.

RAJÉ, F. 2007. Using Q methodology to develop more perceptive insights on transport and social inclusion. Transport Policy, 14, 467-477.

SHOVE, E. 2012. Putting practice into policy: reconfiguring questions of consumption and climate change. Contemporary Social Science, 1-15.

STEELMAN, T. A. and MAGUIRE, L. A. 1999. Understanding participant perspectives: Q methodology in national forest management. Journal of Policy Analysis and Management, 18, 361-388.

STEG, L., VLEK, C. and SLOTEGRAAF, G. 2001. Instrumental-reasoned and symbolic-affective motives for using a motor car. Transportation Research, Part F: Traffic Psychology and Behaviour, 4, 151-169.

STEG, L. 2005. Car use: lust and must. Instrumental, symbolic and affective motives for car use. Transportation Research, Part A, 39, 147-162.

STEPHENSON, W. 1953. The study of behavior: Q-technique and its methodology, Chicago, University of Chicago Press.

STEVENSON, H. 2015. Contemporary discourses of green political economy: A Q method analysis. Journal of Environmental Policy and Planning, Online, 1-21.

TILAHUN, N. ET AL. 2016. Transit use and the work commute: Analyzing the role of last mile issues. Journal of Transport Geography, 54, 359-368.

Tight M., Rajé F. and Timms P. (2017) Car-free urban areas - a radical solution to the last mile problem or a step too far? Built Environment, This issue.

UK DEPARTMENT FOR TRANSPORT. 2015. National Travel Survey: England 2014. Statistical Release.

WALTON, D., SUNSERI, S. 2010 Factors influencing the decision to drive or walk short distances to public transport facilities. International Journal of Sustainable Transport. 4, 212-226.

WATTS, S. and STENNER, P. 2012. Doing Q Methodological Research: Theory, Method and Interpretation, London, Sage. 